\title{
O Programa Nacional de Alimentação Escolar no Instituto Federal Baiano: uma abordagem relacional do processo de implementação
}

\author{
The National School Feeding Program at the Federal Institute \\ Baiano: a relational approach to the implementation process \\ Katia de Fatima Vilela ${ }^{1}$ (D), Alair Ferreira de Freitas ${ }^{2}$ (D), Gustavo Bastos Braga² (1), \\ Rodney Alves Barbosa ${ }^{1}$ (D), João Paulo Louzada Vieira ${ }^{3}$ (D)
}

\begin{abstract}
${ }^{1}$ Grupo de Pesquisa em Políticas Públicas, Arranjos Produtivos e Educação, Instituto Federal de Educação, Ciência e Tecnologia de Minas Gerais (IFMG), São João Evangelista (MG), Brasil. E-mails: kativilela@yahoo.com.br; rodneyab@gmail.com

${ }^{2}$ Programa de Pós-graduação em Extensão Rural, Universidade Federal de Viçosa (UFV), Viçosa (MG), Brasil. E-mails: alairufv@yahoo.com.br; gustavobraga17@gmail.com

3Programa de Pós-graduação em Ciências Sociais, Universidade Federal de Juiz de Fora (UFJF), Juiz de Fora (MG), Brasil. E-mail: joaopaulo.direito@yahoo.com.br
\end{abstract}

\begin{abstract}
Como citar: Vilela, K. F., Freitas, A. F., Braga, G. B., Barbosa, R. A., \& Vieira, J. P. L. (2022). O Programa Nacional de Alimentação Escolar no Instituto Federal Baiano: uma abordagem relacional do processo de implementação. Revista de Economia e Sociologia Rural, 60(spe), e245586. https://doi.org/10.1590/1806-9479.2021.245586
\end{abstract}

\begin{abstract}
Resumo: A Lei n 11.947, de 2009, a mais longínqua política de alimentação escolar brasileira, além de favorecer toda a rede pública de educação básica, agregou um mercado importante para os agricultores familiares, ao certificar que, no mínimo, 30\% dos repasses do Fundo Nacional de Desenvolvimento da Educação (FNDE) devem ser utilizados para adquirir alimentos provenientes da agricultura familiar. Contudo, nos institutos federais, instituições importantes tanto para o âmbito da segurança alimentar e nutricional quanto para o desenvolvimento local e regional, a operacionalização do Programa Nacional de Alimentação Escolar (PNAE) tem sido difícil. Nessas instituições, a implementação é complexa, pois envolve relações sociais entre vários atores, discricionariedades e elementos institucionais. O objetivo deste artigo é apresentar como os atores implementadores, as suas relações sociais e os elementos institucionais podem estimular dinâmicas específicas de implementação do PNAE. Para tanto, o lócus de estudo foi o Instituto Federal de Educação, Ciência e Tecnologia Baiano (IF Baiano), campus Senhor do Bonfim. Como percurso metodológico, foram adotados um estudo de caso de caráter descritivo, de natureza quali-quantitativa, estudos bibliográfico e documental e entrevistas semiestruturadas. A pesquisa revelou que as relações sociais, os elementos institucionais e as especificidades locais influenciam a implementação e os resultados das políticas públicas.
\end{abstract}

Palavras-chave: Institutos Federais, interações sociais, políticas públicas, segurança alimentar.

\begin{abstract}
In 2009, with the enactment of Law number 11.947, the farthest Brazilian school nutritional policy, besides benefiting all the public basic education network, aggregates an important market for the family agriculture. At least 30\% of the National Fund for Education Development's financial allocation must buy food originating from it. However, in the Federal Institutes, important institutions for the nutritional and food security scope as well as for the local and regional development, the National School Nutrition Program (PNAE) operationalization has been difficult. In these institutions, the implementation is complex, it involves social relations among many actors, the discretion of the implementation partners, and intuitional elements This article aims to present how implementing actors, their social relations, and institutional elements, can stimulate the specific dynamics for the Program operationalization. For this purpose, the study locus was the Education, Science, and Technology Federal Institute of Baiano (IF Baiano) in the Senhor do Bonfim Campus. The study case was the methodological path adopted with a descriptive quali-quanti nature, bibliographic and documental study, and semi-structured interviews. The results showed that the social relations, institutional elements, and local specificities influenced the implementation and the public policies results.
\end{abstract}

Keywords: Federal Institutes, social interactions, public policies, nutritional security. 


\section{INTRODUÇÃO}

A alimentação escolar (AE) tem sido foco de estudos de diversos pesquisadores e de discussões sobre agendas políticas em muitos países. No Brasil, essa agenda é formatada por diferentes desenhos de programas e, posteriormente, implementada, monitorada e avaliada por órgãos de controle da União. Nesse processo, vale salientar que a implementação é complexa e pode apresentar falhas. Isso ocorre tanto pela amplitude dos programas quanto pela falta de investimento do Estado, ou até mesmo pela qualificação limitada das equipes governamentais responsáveis por esse percurso.

Nesse contexto, as questões relacionadas à $\mathrm{AE}$ e à valorização da produção local de alimentos contribuem para que muitos pesquisadores voltem suas análises para os diferentes formatos de políticas públicas, realizando ainda um comparativo entre essas políticas sociais no âmbito global (Allaire, 2013; Freitas, 2017). Com isso, ampliam-se os conhecimentos referentes aos processos de transformação econômica e social, aumentando a compreensão teórica e empírica em relação aos mercados institucionais de gêneros alimentícios locais.

No Brasil, o Programa Nacional de Alimentação Escolar (PNAE) é a mais antiga política de AE e a mais proeminente nessa agenda pública. Em sua trajetória, o PNAE passou por várias reformulações, atualizações e ampliações, com destaque para 2009, com a promulgação da Lei $n^{\circ} 11.947$, momento em que o Programa criou um novo mercado para os agricultores familiares, ao garantir que, no mínimo, 30\% dos repasses do Fundo Nacional de Desenvolvimento da Educação (FNDE) deveriam ser utilizados para aquisição de alimentos oriundos da agricultura familiar. Esse fato abriu um precedente histórico, com a dispensa licitatória; consequentemente, as compras de produtos oriundos dos agricultores familiares passaram a ser feitas de forma menos burocrática, mediante "chamadas públicas" (Troian et al., 2020). Esse cenário tanto incentiva o desenvolvimento rural quanto auxilia nele, inserindo os agricultores familiares em um mercado competitivo, ao qual, sem essa dispensa licitatória, eles não teriam a possibilidade de acesso, ou isso seria bastante limitado.

Essas oportunidades se concretizam no cotidiano da agricultura familiar, de suas organizações e dos mediadores sociais que as apoiam, como também dos gestores públicos que buscam operacionalizar os programas, mesmo diante dos desafios à realização de suas intenções e de seus objetivos (Duarte \& Dias, 2012; Silva et al., 2014). Pelo fato de as políticas públicas voltadas para a agricultura familiar exigirem uma maior conexão entre a sociedade e o Estado, não apenas em termos de interação, mas também de troca de informações (Lotta, 2010), os entraves precisam ser solucionados para que o PNAE contemple seu público e realize seus objetivos.

Essa conjuntura justifica pesquisas que tratam das experiências de implementação do Programa, pois auxiliam na ampliação do conhecimento de ações dos atores sociais, bem como de suas relações para lidarem com implicações vivenciadas nesse processo, contribuindo, assim, para a construção, a institucionalização e a efetividade do mercado institucional. Além disso, consolidar a aproximação entre esses atores resulta em maior desempenho do PNAE. Nessa perspectiva, especial atenção deve ser dada aos Institutos Federais (IFs) como entidades executoras do Programa, já que representam um grande potencial de compra para AE e importante capilaridade nacional. No entanto, como demonstrou a revisão de literatura, eles ainda são pouco estudados e se mantêm invisibilizados no contexto nacional, no que tange à implementação do PNAE.

Os IFs são instituições de ensino distribuídas em todo o território brasileiro que atuam na oferta da educação básica (foco do PNAE), profissional e tecnológica. Dentro desse contexto, a compra institucional de alimentos da agricultura familiar se apresenta como estratégia do governo, o qual, por meio da nutrição e da alimentação, atende às demandas da sociedade 
referentes à $A E$, valoriza os hábitos locais e regionais, oferece alimentos saudáveis e nutritivos no ambiente escolar para alunos matriculados na educação básica pública e ainda fomenta estratégias de reprodução para os agricultores familiares em todo o território nacional.

Apesar de sua incontestável importância no âmbito da segurança alimentar e nutricional, bem como para o desenvolvimento local, a execução orçamentária do PNAE por parte dos Institutos Federais de Educação, Ciência e Tecnologia tem sido de difícil operacionalização (Vilela et al., 2019, 2020), uma vez que a implementação e a instrumentalização do Programa envolvem interações sociais e a colaboração dos servidores dos campi'. Outra problemática é em relação ao orçamento do PNAE, o qual nos IFs é regido pelos princípios orçamentários² de unidade (o orçamento é único, ou seja, é da União, e não da instituição), pela universalidade (contendo todas as despesas e receitas referentes ao exercício) e pela anualidade (ano civil, iniciando em $1^{\circ}$ de janeiro e terminando em 31 de dezembro).

Assim, quando a instituição, por motivos diversos, não consegue absorver todo o orçamento empenhado (falta de produtos, ausência de documentações, falta de periodicidade na entrega, ausência ou baixa aproximação com agricultores familiares etc.), o orçamento do PNAE não pode ser reprogramado para o ano civil seguinte, como é feito nas escolas públicas municipais. Desse modo, no fim do exercício, o recurso que sobra deve ser devolvido para a Reitoria, que, por sua vez, retorna-o à União.

Nessa circunstância, os atores implementadores são aqueles que estão na linha de frente da operacionalização do Programa, que vivenciam os limites e as oportunidades no cotidiano de suas atribuições. O conjunto desses fatores pode, muitas vezes, trazer consequências não só para o desenvolvimento de ações efetivas da fase de implementação do PNAE, mas também para o público das políticas públicas. Diante dessas concepções, revela-se o quanto os burocratas de nível de rua ${ }^{3}$, por meio de suas discricionariedades ${ }^{4}$, tomam decisões que levam à ação ou à inércia nos processos que envolvem a operacionalização do Programa.

Destaca-se ainda que, apesar da profusão de estudos sobre o tema, a compra governamental de alimentos da agricultura familiar é relativamente recente, e os arranjos institucionais de implementação são muito dinâmicos, o que justifica a ampliação dos investimentos de pesquisa em busca de elucidações das configurações sociais e dos dispositivos institucionais que condicionam a trajetória e os resultados do Programa nos locais em que ele se realiza. Reconhecendo a complexidade da implementação do PNAE, buscou-se, a partir do caso do Instituto Federal de Educação, Ciência e Tecnologia Baiano (IF Baiano), campus Senhor do Bonfim, mostrar como diferentes atores implementadores, os elementos institucionais e as interações sociais podem estimular dinâmicas particulares de implementação do Programa. Este artigo, com base em um estudo de caso, teve como objetivo compreender as dinâmicas relacionais locais de implementação do PNAE, sinalizando elementos condicionantes da política, subjacentes à burocracia pública e vinculados às interações entre os atores envolvidos no processo de implementação.

1 Campié o plural de campus.

2 SIAFI n 020318; Lei Complementar n 101/2000; Lei Complementar n 4.320/1964; artigo 165 da Constituição Federal de 1988; e Decreto $n^{\circ}$ 93.872/1986.

${ }^{3}$ Trata-se de um conceito para denominar, segundo Lipsky (1976), uma classe específica de trabalhadores que atuam na estrutura burocrática dos governos contemporâneos.

4 Prerrogativa legal conferida aos burocratas de nível de rua para a prática de determinados atos administrativos, com liberdade de escolhas. 


\section{ABORDAGEM RELACIONAL DA IMPLEMENTAÇÃO DO PNAE}

Até meados da década de 1960, a ciência econômica focalizava as operações econômicas como seu objeto de estudo, e a sociologia ocupava-se em analisar as consequências sociais advindas das transformações econômicas, mantendo, assim, uma separação entre sociólogos e economistas (Serva \& Andion, 2006). De acordo com Swedberg (2004), naquela época, o pensamento de Max Weber já ressoava, construindo pontes entre essas disciplinas, as quais tratavam tanto dos fenômenos econômicos quanto daqueles economicamente condicionados e suas influências na sociedade.

No campo da compreensão sociológica de fenômenos econômicos, merece destaque especial o conceito de social embeddedness (imersão social), que se iniciou com a publicação do livro "A Grande Transformação", de Karl Polanyi (1980 [1944]), obra em que o autor analisou, sob as lentes socioantropológicas, as dessemelhanças entre os diversos sistemas sociais e econômicos e suas transformações históricas. Posteriormente, Mark Granovetter sugeriu fundir as ideias de Karl Polanyi sobre "imersão" com a noção de redes sociais, rompendo com abordagens sub e supersocializadas. Essa visão percebe o comportamento econômico imerso em redes de relações interpessoais. A noção de embeddedness imediatamente leva a duas questões: (i) "A economia encontra-se enraizada em quê?" e (ii) "Qual é o grau desse enraizamento?" (Wilkinson, 2002). Essa é uma das perspectivas fundantes da chamada Nova Sociologia Econômica (NSE), que reinaugura a integração entre economia e sociologia como campo científico, ressignificando a construção social dos mercados e a imersão social da vida econômica.

Segundo Granovetter (1985), em seu artigo seminal, a ação é sempre socialmente contextualizada e não pode ser explicada apenas pelas motivações e pelos interesses individuais que a deflagraram. Em alinhamento a essa afirmação, que demonstra seu posicionamento ontológico, o autor reforça também que as instituições são socialmente construídas e podem ser alteradas a partir da configuração e da estrutura das relações sociais. Para Steiner (2006), a NSE não anula o comportamento egoísta dos indivíduos, no entanto descarta isso como princípio e pedra filosofal da explicação da ação econômica. Para o autor, "a definição proposta por Granovetter e as reflexões provindas da sociologia econômica do começo do século XX mostram que os conceitos de ação e instituição continuam, ontem como hoje, essenciais para o desenvolvimento da sociologia econômica" (Steiner, 2006, p. 30).

A NSE tem como um de seus núcleos principais a análise sociológica dos mercados, entendendo-os também como consequência da ação social e condicionados pela interação de atores diversos, orientados pelos seus interesses, mas influenciados também pelas instituições sociais. Como afirmou Steiner (2006, p. 37), “o mercado é, então, um mercado de encontro, no sentido de que as interações concretas entre os indivíduos estão no centro dessa iniciativa". Nesse sentido, entender os diversos mercados como socialmente construídos quer dizer que sua compreensão passa, necessariamente, por evidenciar de forma empírica os atores e suas interações, bem como as articulações que cercam as transações econômicas. Nesse ínterim, contextualizar institucionalmente os comportamentos sociais e as relações entre os atores é basilar para desvelar os condicionantes das redes sociais que se estruturam para a operação dos mercados.

Essa perspectiva contribui para delinear uma abordagem relacional para a implementação de políticas públicas, considerando que o foco analítico se ajusta a partir das interdependências entre os atores, ou seja, de uma concepção de que as políticas públicas e os mercados que delas decorrem são socialmente construídos. Nesse sentido, é fundamental a análise contextualizada dos casos, pois as configurações das redes sociais, formadas por relações assimétricas, são sempre particulares a cada território e condicionadas por sua história. Nessa composição, o 
significado que os atores constroem de si e dos demais é tão essencial quanto a estrutura da rede da qual fazem parte (Friedland \& Alford, 1991). Portanto, a NSE oferece conceitos que instigam a construção de referências de análise tanto de indivíduos quanto das instituições e podem auxiliar, assim, na análise das interações entre sociedade e Estado para a implementação de políticas públicas.

A teoria das redes representa relações simétricas e assimétricas no campo de estudo. Uma das aplicações que merece destaque nessa teoria é a possibilidade de análise dos relacionamentos sociais entre os atores, uma vez que esses indivíduos podem pertencer a grupos, corporações ou nacionalidades diferentes (Wasserman \& Faust, 1994). Nesse sentido, Borgatti \& Li (2009) ressaltam que, ao utilizar a teoria das redes sociais, é necessário ter como proposição essencial a percepção de que entre os atores há uma relação de interdependência.

A Social Network Analysis (SNA), ou seja, a análise de redes nas Ciências Sociais, é utilizada para compreender os fluxos de comunicação e de informações entre os indivíduos (Autry \& Griffis, 2008), que podem ser condicionados como atores sociais dentro de uma organização, revelando o grau de densidade, a centralidade de grau dos indivíduos que atuam em rede, seus fluxos e conexões estruturais múltiplos e as relações que essas conexões constituem (Wasserman \& Faust, 1994). Essa abordagem passou a ser apropriada como instrumento metodológico, e não apenas metafórico, na descrição da realidade social, sendo adequada tanto ao campo das Ciências Humanas e Sociais quanto ao campo das Ciências Exatas.

Visando avaliar como as dinâmicas relacionais e os aspectos institucionais que contextualizam o PNAE afetam a trajetória e os resultados do Programa, neste estudo credita-se especial atenção à rede social que suporta o processo de implementação do Programa no IF Baiano/SB, desvelando os atores que ajudam a construir socialmente a realidade da compra institucional de alimentos da agricultura familiar. Os atores locais observam, ouvem, agem, efetivam o Programa e definem fluxos de relações unidirecionais e bidirecionais. Logo, a imersão das ações vinculadas ao PNAE nessa rede social imprime características particulares ao modo como o Programa é operacionalizado nos contextos locais (Freitas, 2017). Esse conceito contribui para a compreensão das alternativas e técnicas adotadas pelos atores implementadores imersos em redes sociais, ou seja, o enraizamento ajuda na percepção das maneiras peculiares com as quais a mesma política pública assume características diferentes em distintos contextos.

Outro ponto importante diz respeito aos aspectos relacionais de reciprocidade entre os atores que atuam em rede, com foco nos laços, ou seja, na forma como os nós da rede estão interligados uns com os outros e na concepção de laços fracos e fortes (weak ties e strong ties), criada por Granovetter (1973). De acordo com o autor, a força de um laço possui aglutinação (supostamente linear) em relação ao montante de tempo, à expressividade emocional, à confiança e à reciprocidade que qualificam o laço. Nesse sentido, mais do que descrever os padrões estruturais da rede em determinado momento como uma apreensão morfológica, é necessário compreender a natureza dessas relações, ou seja, os elementos não econômicos subjacentes à ação individual e aos arranjos coletivos.

\section{METODOLOGIA}

Metodologicamente, este trabalho foi construído por meio de um estudo de caso de caráter descritivo, de natureza quali-quantitativa (Gil, 2017), que se apropria da análise de redes sociais como orientação analítica e ferramenta metodológica. A pesquisa documental foi elaborada a partir de materiais disponibilizados pelo IF Baiano/SB, cujos dados permitiram analisar a implementação do Programa na instituição. A pesquisa de campo ocorreu in loco na Reitoria 
do IF Baiano, em Salvador, e no campus Senhor do Bonfim, em agosto de 2019. Em Salvador, foram entrevistados o reitor da instituição e os demais servidores que atuam na descentralização dos recursos do PNAE e apoiam os campi na execução orçamentária do Programa.

Com o intuito de obter mais informações sobre o PNAE no IF Baiano/SB, foram entrevistados três fornecedores do Programa ligados à agricultura familiar e também três servidores do IF oriundos de outros campi, pois, durante as entrevistas, esses servidores foram citados como atores relevantes para a implementação do Programa no IF Baiano. Ao todo, foram entrevistados 20 atores. Para analisar os dados qualitativos obtidos por meio de entrevistas e dos questionários aplicados a todos esses informantes, foi realizada a análise de conteúdo (Bardin, 2011). Já as informações colhidas durante a pesquisa de campo, para preenchimento da matriz de análise de rede social e posterior tabulação dos dados em Excel, foram convertidas do formato Excel para formatos \#\#d e \#\#h, apropriadas para a leitura do software UCINET 6 e NetDraw ${ }^{5}$. O método quantitativo foi útil para dimensionar e extrair elementos gerais da rede de implementadores que atuam com a operacionalização do Programa, como: densidade, reciprocidade, coesão, centralização de grau etc. Nessa perspectiva, Pereira et al. (2018) e Yin (2015) enfatizam que, nos estudos de caso, a junção de métodos qualitativos e quantitativos se complementam e permitem o melhor entendimento dos fenômenos sociais analisados.

Faz-se pertinente evidenciar que este estudo foi realizado em observância à Resolução $n^{\circ}$ 466/2012, do Conselho Nacional de Saúde, submetido ao Comitê de Ética da Universidade Federal de Viçosa, em Viçosa, Minas Gerais, e aprovado por ele. Por fim, com o intuito de preservar a identidade dos 20 entrevistados, foram utilizados pseudônimos, como pode ser observado no Quadro 1.

Quadro 1 - Perfil geral das(os) entrevistadas(os), Bahia.

\begin{tabular}{|l|l|}
\multicolumn{2}{|c|}{ Identificação na rede Instituição } \\
\hline BA_A $(r)$ & Reitoria do IF Baiano \\
\hline BA_B $(r)$ & Reitoria do IF Baiano \\
\hline BA_C $(r)$ & Reitoria do IF Baiano \\
\hline BA_D $(r)$ & Reitoria do IF Baiano \\
\hline BA_E (d) & Docente do IF Baiano/SB \\
\hline BA_F (t) & Técnico administrativo do IF Baiano/SB \\
\hline BA_G (t) & Técnico administrativo do IF Baiano/SB \\
\hline BA_H (t) & Técnico administrativo do IF Baiano/SB \\
\hline BA_I (af)(ex-aluna)(ex-terc) & Agricultor familiar \\
\hline BA_J (af) & Agricultor familiar \\
\hline BA_K (af) & Agricultor familiar \\
\hline BA_L (oc) & Técnico administrativo do IF Baiano - outro \\
& campus \\
\hline BA_M (oc) & Docente do IF Baiano - outro campus \\
\hline BA_N (d) & Docente do IF Baiano/SB \\
\hline BA_O (t) & Técnico administrativo do IF Baiano/SB \\
\hline curso técnico em Agropecuária & IF Baiano/SB \\
\hline curso técnico em Zootecnia & IF Baiano/SB \\
\hline curso técnico em Alimentos & IF Baiano/SB \\
\hline curso técnico em Agrimensura & IF Baiano/SB \\
\hline licenciatura em Ciências Agrárias & IF Baiano/SB \\
\hline
\end{tabular}

Nota: (t) técnico administrativo; (d) docente; (oc) outro campus; (r) Reitoria; (af) agricultor familiar. Fonte: elaborado pelos autores (2020).

${ }^{5}$ Com o auxílio dos softwares Ucinet 6 e NetDraw para sua estruturação (Borgatti et al., 2002). 
Constata-se no Quadro 1 que a maioria dos entrevistados (80\%) é do IF Baiano Reitoria, outros campi e campus Senhor do Bonfim e que $20 \%$ são fornecedores do Programa. Vale destacar que os informantes da Reitoria do IF Baiano, no campus Senhor do Bonfim, e os servidores de outros campi da instituição foram selecionados em razão de suas atuações diretas e indiretas referentes ao PNAE, o que culminou na efetivação do Programa na instituição como um todo. Já em relação aos agricultores familiares, foram entrevistados aqueles fornecedores que aceitaram participar da pesquisa. As análises que se seguem foram construídas a partir da descrição dos dados coletados, associados à revisão de literatura realizada. O conjunto de dados, oriundos da triangulação de métodos de pesquisa, foi cotejado e confrontado com a abordagem teórica definida, buscando-se dotar de sentido os resultados expostos a seguir. Não se esperava o esgotamento das possibilidades analíticas e de evidências empíricas, mas, diante da pesquisa aqui delineada, foram elucidados aspectos subjacentes à implementação do PNAE no caso em tela.

\section{RESULTADOS E DISCUSSÕES}

\subsection{Contextualização do IF Baiano/SB e da adesão ao PNAE}

O IF Baiano conta com uma Reitoria localizada em Salvador e 14 campi, situados em diferentes cidades da Bahia (Figura 1). A instituição oferece 194 cursos para 13.324 alunos matriculados na educação básica (Plataforma Nilo Peçanha, 2020). Todas as unidades possuem vocação agrícola, conforme Portaria n²46, de 15 de abril de 2016, do Ministério da Educação, publicada no Diário Oficial da União (caracterizando o IF Baiano como instituição agrícola).

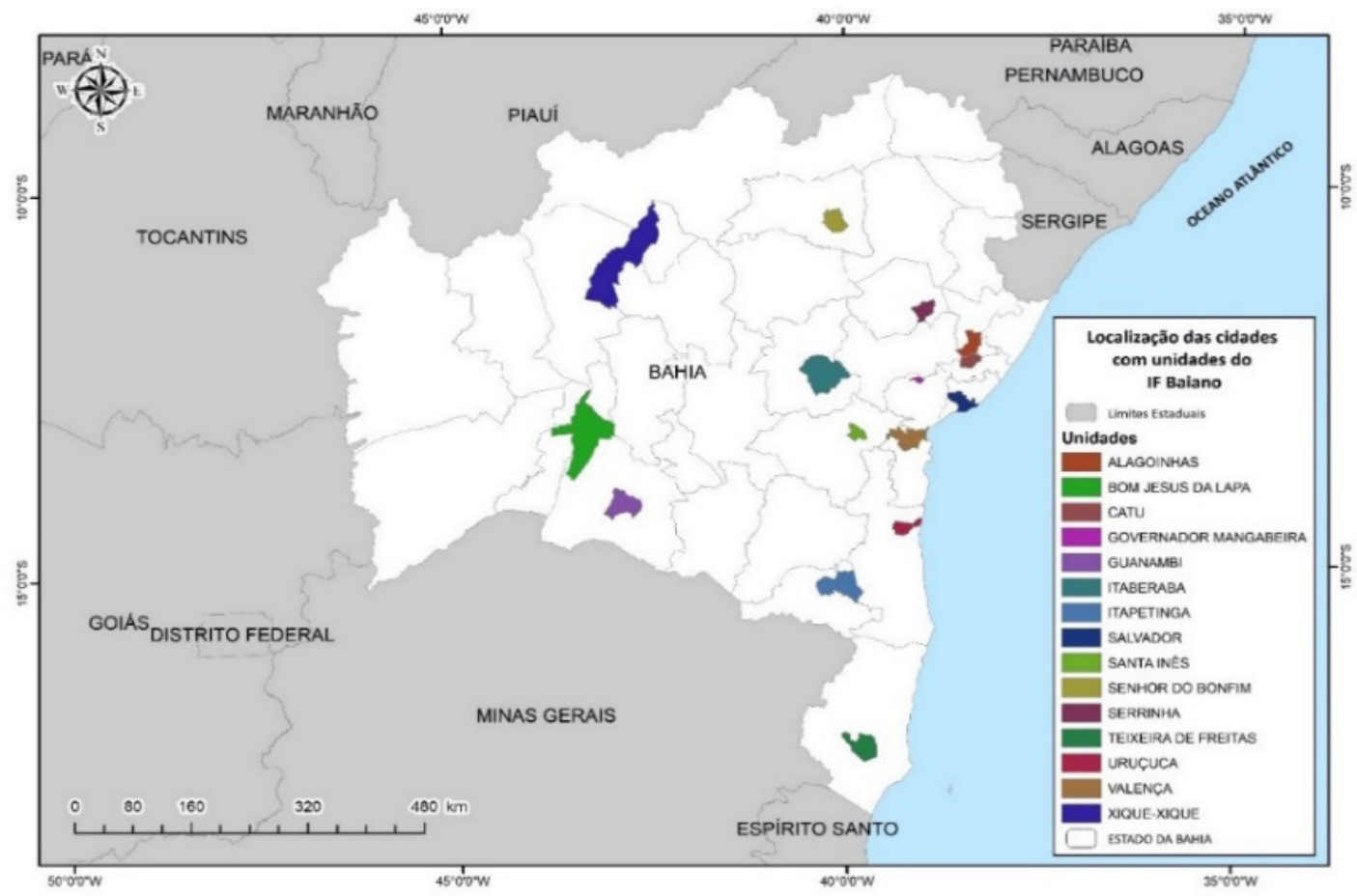

Figura 1. Localização das cidades com campus do IF Baiano. Fonte: elaborada pelos autores a partir dos dados da Plataforma Nilo Peçanha (2020). 
O IF Baiano agrega as antigas Escolas Agrotécnicas Federais e as Escolas Médias de Agropecuária Regionais (EMARC) da Comissão Executiva do Plano da Lavoura Cacaueira (CEPLAC), presentes na Bahia. No IF Baiano, todos os campi, além de possuírem cursos voltados para o desenvolvimento rural, também mantêm proximidade com os agricultores familiares da região.

\subsection{Construção Social da Implementação do PNAE no IF Baiano/SB: Operacionalização e Implementadores}

O campus Senhor do Bonfim iniciou sua história em 1993, institucionalizado por meio da Lei n 8.670/93, surgindo, assim, a Escola Agrotécnica Federal de Senhor do Bonfim. Após várias alterações, em 2008 essa escola se transformou em Instituto Federal de Educação. Hoje, o campus, com 27 anos, oferta 11 cursos para 1.368 alunos da educação básica.

O campus Senhor do Bonfim está localizado na Estrada da Igara, s/n, zona rural do município de Senhor do Bonfim, Bahia. Essa instituição de ensino, pertencente à Rede Federal de Educação Profissional, Científica e Tecnológica, oferta cursos de nível médio, como: técnico em Agropecuária integrado ao Ensino Médio, técnico em Zootecnia, técnico em Alimentos, técnico em Manutenção e Suporte de Informática e técnico em Agrimensura, na modalidade subsequente.

Já no quesito cursos superiores, a instituição oferece licenciatura em Ciências da Computação e Ciências Agrárias e pós-graduação lato sensu em Desenvolvimento Sustentável no Semiárido, com ênfase em Recursos Hídricos. Além disso, são ofertados, na modalidade de educação a distância, os cursos: Técnicos em Meio Ambiente, Segurança do Trabalho, Serviços Públicos, Alimentação Escolar, Agente Comunitário de Saúde, Eventos, Administração, Hospedagem e Transações Imobiliárias. A instituição atua com o PNAE desde 2012, ano em que, entre os campi do IF Baiano que executaram o Programa, o campus Senhor do Bonfim destacou-se como aquele que conseguiu operacionalizar o maior valor na instituição, fazendo desde o início da institucionalização do PNAE um trabalho muito interessante. Nesse sentido, BA_A (r) salienta que:

[...], como a instituição sempre teve uma ligação muito próxima dos agricultores familiares do município e região, fizemos reuniões com os agricultores familiares, demonstrando o que tínhamos de recursos e as possibilidades do Programa para o desenvolvimento local. (Entrevistado BA_A(r)).

Nessa perspectiva, o entrevistado BA_A(r) esclarece que o campus IF Baiano/SB é uma instituição que possui o lema de "não devolver recurso", uma vez que sempre se empenhou em utilizar todos os recursos, não só os do PNAE. Dando sequência, BA_A(r) destaca que trabalha na instituição há 21 anos: primeiro atuou como professor substituto, depois como professor convidado, efetivando-se em 2003. Nesse período, ele considera relevante reforçar que:

\footnotetext{
Eu já tinha afinidade com a agricultura familiar mesmo antes de ser servidor do IF Baiano. Dois anos antes de entrar no IF, eu fazia aplicação do PRONAF, atuando como engenheiro agrônomo cadastrado ao Banco do Brasil e Banco do Nordeste. No Instituto Federal, tive maior aproximação com a agricultura familiar da região. Como atividade de extensão, tínhamos projeto que levávamos os alunos no campo (rural) para fazermos demonstrações de procedimentos. Discutíamos e elegíamos os temas com os alunos, víamos o que podia influenciar positivamente na produção, identificávamos propriedades que estavam dentro do aspecto de agricultura familiar e íamos fazer intervenções naqueles espaços, chamávamos os agricultores familiares da região e fazíamos as demonstraç̃oes. Fazíamos um trabalho muito próximo ao Banco do Brasil, que era quem financiava esses agricultores na época. Inclusive muitas dessas intervenções eram realizadas em uma propriedade coletiva financiada pelo Banco do Brasil. Ainda existe essa propriedade até hoje em Senhor do Bonfim, e era lá que concentrávamos nossos trabalhos. (Entrevistado BA_A(r)).
} 
Observa-se que a trajetória de BA_A(r) foi um passo determinante para a amplitude de suas ações no percurso do Programa no IF Baiano. Para Hall \& Taylor (2003), o conceito "path dependence", ou de dependência da trajetória, evidencia o desenvolvimento das instituições ao longo da história, sendo relevante para explicar os processos das políticas públicas e as situações específicas, bem como para compreender as escolhas dos atores. Na perspectiva do depoimento de BA_A(r), a entrevistada BA_I(af)(ex-aluna)(ex-terc) afirma que a gestão do IF Baiano/SB sempre foi excelente de comunicação, inclusive possuindo aproximação com os alunos, técnicos administrativos, docentes, terceirizados e agricultores familiares. Relata também que, quando começou a conversar com a gestão do campus sobre o PNAE, ela já tinha vivido uma experiência em uma cooperativa e identificado as necessidades dos agricultores familiares do município e da região. Por conhecer a produção agropecuária local, ela já havia procurado formas de escoamento dos produtos produzidos localmente. BA_I(af)(ex-aluna) (ex-terc) ainda frisa que:

\begin{abstract}
Nosso primeiro projeto da cooperativa com a CONAB foi trabalhoso, porque não conhecíamos o processo, tínhamos que aprender. Tem muita burocracia, tem toda uma didática para seguir. Eles mudam o processo direto, a sede da CONAB é em Salvador, muito distante para nós, então caímos e levantamos e fomos seguindo graças ao apoio da gestão do IF Baiano Senhor do Bonfim, que sempre ofertou capacitações para nós do rural. Para se ter uma ideia, a gestão do campus deixou que nossa cooperativa viesse despolpar umbu na agroindústria da instituição. Essa parceria possibilitou que conseguíssemos entregar nosso produto; sem esse auxílio não teríamos conseguido. (Entrevistada BA_I(af)(ex-aluna)(ex-terc)).
\end{abstract}

Logo, o campus Senhor do Bonfim possui característica de inserção dos agricultores familiares e de participação intensa das atividades agropecuárias locais e regionais. Identifica-se, nesse caso, a reprodução das relações de proximidade e de confiança, o que facilita a cooperação no processo de implementação do PNAE, reforçando o argumento de Freitas (2015) de que os resultados das políticas podem ser condicionados pelas negociações entre os atores envolvidos no processo. Os dados explicitam, assim, que a natureza das relações estabelecidas entre gestores do IF e agricultores familiares transcende a instrumentalidade da operacionalização de uma política e conota sinergias ao vínculo histórico de territorialização das parcerias.

A instituição sempre manteve relação próxima com o agricultor familiar, seja como partícipe ativo, realizador ou mesmo organizador de eventos voltados para o meio rural. Segundo BA_A(r):

\footnotetext{
Essas ações facilitaram muito o campus na identificação de lideranças, entidades, organizações; além do mais, essa aproximação sempre fluiu com facilidade, e isso é algo que não se consegue fazer da noite para o dia; isso é um processo, uma construção social. (Entrevistado BA_A(r)).
}

Percebe-se pelos depoimentos de BA_A(r) e BA_I(af)(ex-aluna)(ex-terc) que a relação do IF Baiano/SB, como órgão federal edificado sobre o ensino, a pesquisa e a extensão em parceria com os agricultores familiares, é fortalecida por meio das ações de extensão da instituição. A extensão torna-se importante, pois, além de promover essa aproximação, contribui para que as dificuldades de efetivação, tanto do órgão executor quanto dos fornecedores, sejam esclarecidas entre a instituição federal e os próprios fornecedores. Assim, essa atividade extensionista se torna um modelo sustentável, em que a parceria entre esses atores vai sanando e minimizando os entraves de acesso e abastecimento no mercado institucional. Isso também fortalece as relações entre ambas, em um canal em que a instituição busca atender às necessidades dos agricultores familiares, e vice-versa. Essa aproximação ainda possibilita capacitar os agricultores familiares para acessarem os mercados, conforme relatado por BA_A(r):

No intuito de capacitar os agricultores familiares, nosso processo seletivo era diferenciado. Tínhamos a possibilidade de equilibrar o ingresso de alunos oriundos do meio rural e alunos do urbano, onde a entrevista 
tinha o mesmo peso da nota da prova. Isso facilitava que muitos alunos oriundos da agricultura familiar estivessem dentro do Instituto Federal de Senhor do Bonfim, e essa condição nos deu inclusive a possibilidade de quando surgiu o recurso do PNAE, muitos desses alunos já estarem organizados em associação e cooperativa e serem nossos fornecedores. A exemplo temos nossa ex-aluna BA_l(af)(ex-aluna)(ex-terc), que fez o curso técnico em Alimentos. Ela é oriunda do rural e hoje está à frente de uma cooperativa que é uma das nossas fornecedoras do Programa. (Entrevistado BA_A (r)).

Nesse sentido, BA_I(af)(ex-aluna)(ex-terc) afirma ter sido aluna do IF Baiano/SB e que, assim que terminou o curso técnico em Alimentos, foi contratada para trabalhar como terceirizada na agroindústria do campus, onde ficou por três anos. Segundo ela, no período em que ainda era terceirizada, foi procurada por agricultores familiares que estavam tendo muita dificuldade de escoar seus produtos e até pensando em desistir, porque não sabiam mais o que fazer para conseguir esse escoamento. A perda de excedentes era muito alta, pois o que eles consumiam da produção era pouco, mas não dava para plantar só para consumo e deixar o restante da propriedade ociosa.

Essa entrevistada ainda salienta que a agricultura familiar no município de Senhor do Bonfim é forte, porém o escoamento da produção ainda é incipiente. Antes da atuação de BA_I (af)(exaluna)(ex-terc), os agricultores familiares da região escoavam suas produções na feira livre, mas, quando não conseguiam vender todo o excedente produzido, eles acabavam desestimulados e deixavam de plantar, migrando para outras cidades, inclusive para os grandes centros urbanos.

Por consequência, BA_I(af)(ex-aluna)(ex-terc) enfatiza que decidiu sair do IF Baiano/SB e constituir uma cooperativa, com a missão de dar esse apoio aos agricultores familiares da região. Explica que seu trabalho consiste em ir até as propriedades e realizar um levantamento do que os agricultores familiares produzem (excedente e consumo). Ela relata que, fazendo uma pesquisa de mercado, percebeu que as feiras livres não tinham mais capacidade de consumir todo o excedente dos produtos daqueles agricultores familiares. Isso porque o volume de produtos levados para as feiras era alto, e o consumidor já não conseguia absorver toda a produção ofertada. Percebeu também que, por falta de preparo dos agricultores familiares, todos estavam cultivando os mesmos produtos, criando um montante que não era absorvido pelo mercado local. A partir daí, a cooperativa começou a instruir os agricultores familiares a diversificar a plantação para facilitar o escoamento do que produziam.

Esse processo sinaliza a construção de vínculos que romperam com um "buraco estrutural", integrando a realidade e a rede dos agricultores familiares à realidade e à rede social dos agentes do IF. A centralidade assumida por aquela pessoa, que já integrava o IF Baiano, foi importante para definir relações de proximidade e confiança com os gestores do IF e, assim, dinamizar os diálogos e a aproximação entre as diferentes realidades no âmbito do PNAE.

BA_I(af)(ex-aluna)(ex-terc) finaliza dizendo que sua iniciativa foi de extrema importância, pois, quando começaram as chamadas do PNAE, os agricultores familiares já estavam aptos a participar. E aproveitando a aproximação com o IF Baiano/SB, a gestão da cooperativa dirigiuse ao IF, apresentando o desejo de trabalhar em conjunto com as entregas ao PNAE. Especial atenção deve ser dada à ampliação dos processos de capacitação dos potenciais fornecedores do mercado institucional, seja preparando os agricultores para elaboração dos projetos de venda, seja treinando-os para beneficiar os produtos e ainda dando-lhes orientações com relação à ampliação/diversificação da produção para atender à demanda do mercado institucional, dos custos etc.

A gestão do campus assevera que se preocupa com a capacitação voltada para a atuação rural desde o processo seletivo de alunos, dando chances aos oriundos do meio rural para se capacitarem e levarem os conhecimentos adquiridos a suas comunidades. O IF Baiano/SB, como 
órgão executor do Programa, consegue, por meio de suas ações de extensão, demonstrar aos agricultores familiares os passos para que suas atividades sejam mais especializadas:

O campus respira muito o agrícola. Fazemos articulação com agricultores, os trazemos para o campus no intuito de construir links e parcerias, e isso abre muito as portas para nós, e eles passam a nos enxergar como uma instituição com potencial para auxiliá-los nas diversas produções, mas também nos processos relativos a acesso aos mercados. (Entrevistado BA_E(d)).

Esse entrevistado relatou que o IF Baiano/SB sempre promove eventos, por meio da sua coordenação de extensão, com outros docentes da instituição. Ao serem questionados se existe no campus algum programa de ensino, pesquisa e extensão envolvendo a temática PNAE, $B A \_B(r)$ argumentou que não, mas enfatizou o papel da agricultura como um todo, citando o exemplo dos sistemas agrícolas mandalas, que são desenvolvidos no campus, entre outras ações que são constantes, como:

Fazemos para ensinar os agricultores familiares a produzirem (doce, iogurte, queijo), ou seja, nossa preocupação é profissionalizar suas potencialidades, para que assim possam ter condições de fornecer seus excedentes não só para campus. Em agosto de 2019 (mês das entrevistas de campo), vamos trazer 125 agricultores familiares para dentro da instituição. Eles irão fazer uma capacitação em cinco cursos aqui dentro, em espaços diferentes da nossa instituição, então eles irão trabalhar com compostagem, palma irrigada, construção de tanques para captação de água, como trabalhar com defensivo agrícola natural, tudo feito pelos professores daqui. (Entrevistado BA_E(d)).

Os docentes do IF Baiano/SB ofertam essas ações durante o ano todo, em espécie de ciclos, e a temática é definida de acordo com as demandas das comunidades rurais local e regional. Essas ações, ao longo do ano, facilitam o acesso dos agricultores familiares ao PNAE, e a sua operacionalização por parte do campus é um trabalho conjunto. Ainda nessa perspectiva de capacitações dos agricultores familiares, BA_E(d) argumenta que:

Em outros momentos, o SENAR (Serviço Nacional de Aprendizagem Rural) traz para dentro do campus alguns agricultores familiares para fazerem cursos de forragicultura, derivados de leite para trabalhar com queijos, manteiga e iogurte, e um outro para trabalhar com cortes finos de caprinos e ovinos. Sempre temos eventos no campus e sempre buscamos trazer os agricultores familiares para dentro da instituição, porque aqui temos toda a estrutura necessária para realizar capacitações com eles. (Entrevistado BA_E(d)).

Esse entrevistado ainda afirma que:

A proposta da instituição é de fortalecer a agricultura e pecuária na região, e que este tem sido o foco dos servidores técnicos-administrativos e docentes. Pois, como evidenciado anteriormente, o IF Baiano funda suas raízes no meio rural, sendo a relação com as comunidades rurais de grande importância para a instituição. Para que seja possível estreitar os laços entre a instituição e a comunidade, apesar de a Regulamentação da Atividade Docente (RAD) institucionalizar uma carga horária de até 16 horas semanais para os docentes, que convertendo em aulas daria 19 aulas semanais, o IF Baiano, ciente da importância dos outros eixos, delimita uma carga horária de "14 a 16 aulas, de modo que estimule os professores a realizar a pesquisa, a extensão e a participarem de comissões". (Entrevistado BA_E(d)).

Sobre essas afirmações de BA_E(d) com relação à carga horária dos docentes do IF Baiano/ SB, há nos IFs um regulamento denominado Regulamento de Atividade Docente (RAD), em que essa normativa, em consonância com os princípios que regem os IFs, criados nos termos da Lei $\mathrm{n}^{\circ}$ 11.892/2008, visa regulamentar as atividades docentes da Carreira do Magistério do Ensino Básico, Técnico e Tecnológico. Vale destacar que os RADs são deliberados pelos Conselhos Superiores de cada instituição da rede, sendo possível encontrar diferentes regulamentos para a atividade docente.

No IF Baiano/SB, as diretrizes do RAD encontram-se divididas em questões que vão desde o desenvolvimento das atividades de planejamento, execução, acompanhamento, avaliação 
da carga horária e do regime de trabalho docente, no que diz respeito à equalização das atividades de ensino, pesquisa, extensão, gestão, representação institucional, até a valorização do trabalho docente e da qualidade dos serviços prestados pela instituição. $\mathrm{O}$ artigo 36 do RAD (Instituto Federal de Educação, Ciência e Tecnologia Baiano, 2019, p. 12) limita a carga horária semanal dedicada à realização das atividades previstas nesse Regulamento, sendo: i) no mínimo 10 horas e no máximo 16 horas semanais, para os docentes em regime de tempo integral; e ii) no mínimo 8 horas e no máximo 12 horas semanais, para os docentes em regime de tempo parcial.

Já o artigo 17 do RAD (Instituto Federal de Educação, Ciência e Tecnologia Baiano, 2019, p. 7) trata das atividades de extensão, englobando processos educativos, artísticos, culturais, esportivos, científicos e tecnológicos desenvolvidos com pessoas, grupos e comunidades, articulados ao ensino e à pesquisa, e implicando compartilhamento mútuo entre o IF Baiano e a comunidade externa. Segundo o $\$ 1^{\circ}$ desse artigo, as atividades de extensão podem ser de iniciativa do(s) servidor(es), de interesse institucional e/ou por demanda da comunidade, sendo esse instrumento normativo um dos fatores que tem contribuído para a execução do PNAE no campus. Assim, as instituições podem tanto estimular quanto constranger as escolhas e condutas dos atores. Como afirmou Scott (1991), as instituições vistas como estruturas e atividades cognitivas, normativas e reguladoras evidenciam o comportamento social.

Percebe-se que a extensão é importante no IF Baiano, pois se trata de um mecanismo institucional que promove a conexão com a agricultura familiar. Ela se caracteriza como uma das formas de compartilhar com a comunidade os conhecimentos desenvolvidos na instituição, o que auxilia os agricultores familiares a acessar os mercados em geral. Os entrevistados foram questionados se, para iniciar o processo de implementação, a instituição constituiu uma comissão designando servidores para fazer a sensibilização e a articulações do Programa, e os entrevistados $B A \_F(t), B A \_E(d), B A \_G(t), B A \_H(t)$ e $B A \_C(r)$ relataram que:

Não criamos não, foi muito natural mesmo. Não temos comissão, sempre funcionou sem comissão. Aqui é assim, BA_G(t), BA_H(t) atuam com BA_F(t), é bem simples, e o PNAE acontece. O setor de compras aqui é muito preparado, ele, muitas vezes, é que vem aqui e me puxa, olha temos $R \$ 96.0000,00$ de PNAE, temos que executar. A comunicação entre setores, além da capacitação do setor de compras e a parceria comigo na nutrição, é o nosso diferencial. É preciso ter sintonia, se não o recurso não é usado e volta, as coisas precisam caminhar. Se eles não me avisarem que tem esse recurso disponível, eu também não vou saber. (Entrevistados $B A_{-} F(t) ; B A F(d) ; B A \_G(t) ; B A \_H(t) ; e$ BA_C $\left.(r)\right)$.

A boa comunicação entre os servidores envolvidos com a implementação do PNAE na instituição é citada como algo importante e que auxilia no sucesso da operacionalização do Programa. Percebe-se que o processo de execução do PNAE no campus é enxuto e que poucos servidores trabalham com a sua efetivação formal. No serviço público, existe a burocracia como forma de organizar os serviços e ordenar as rotinas, a autoridade e as responsabilidades. Essa estruturação é necessária para que não haja desperdício do dinheiro público. Contudo, o excesso de burocracia no serviço público, alinhado à autonomia limitada (IFs) e à accountability, faz que as ações se tornem morosas, longas e, consequentemente, ineficientes, uma vez que, muitas vezes, esse excesso de processos no setor público, em especial tratando do PNAE, perde-se em suas demasiadas tramitações, o que pode terminar em devolução do orçamento para União, sem a execução da política.

Os entrevistados ainda demonstram que a união deles no início da implementação faz com que os demais campi consigam operacionalizar os recursos. De acordo com BA_B(r), os campi tentam extrapolar os 30\%, que são o mínimo, o que pode ser evidenciado nas falas de BA_C(r) e BA_B(r): 
O desempenho da nossa instituição melhorou muito, principalmente depois que tivemos o interesse, nos unimos e organizamos a implementação do Programa no IF Baiano, ou seja, ao deixarmos o individualismo de lado, o PNAE fluiu na instituição. O Programa é fenomenal, ele melhora a distribuição de renda local, promove saúde para aluno que está consumindo os produtos, o percentual estabelecido pela política pública deveria ser maior que 30\%. Nossos campitentam extrapolar os 30\%, que é o mínimo. Alguns já conseguem, principalmente onde os agricultores familiares são mais organizados. (Entrevistados BA_C(r) e BA_B(r)).

Considerando que a agricultura familiar é um importante fornecedor de alimentos no país e ressaltando que uma das finalidades da criação do IF (Artigo $6^{\circ}$ da Lei $n^{\circ} 11.892 / 08$ ) é contemplar suas ações no desenvolvimento regional, e ainda com base nas reflexões dos argumentos contidos no trabalho publicado em 1940 por Josué de Castro, foram abertas discussões voltadas para o problema da fome e da pobreza no Brasil como uma questão social e política (Pena, 2020). Nessa mesma época, ou seja, 1940, o Instituto de Nutrição levantou um debate sobre o papel do governo federal diante desse cenário de pobreza e fome, o que resultou na conclusão de que o Estado deveria ofertar a alimentação gratuita nas escolas. Os entrevistados começaram a falar da importância do Programa de Alimentação Escolar para o município, conforme atestam os relatos que se seguem:

\begin{abstract}
Acho excelente o PNAE, porque é uma política pública voltada para quem realmente precisa, principalmente aqui, essa região é muito carente. Nós temos alunos muito, muito pobres. Eu sei que muitos deles estudam aqui porque precisam dessa alimentação, eu sei que é fundamental o PNAE para os alunos, e dentro do campus eu acho que funciona bem. É claro que toda gestão a gente sempre pode estar melhorando, eu não diria que nosso campus é perfeito, eu acho que perfeição está distante, mas nós buscamos estar atendendo à demanda de uma forma satisfatória sempre, e a gente tem consciência que temos de estar melhorando. (Entrevistado BA_F(t)).
\end{abstract}

O PNAE tem uma importância enorme na economia local, na agregação de renda para agricultores familiares. Eu já tive fases da cooperativa que algumas famílias chegavam para mim e diziam que conseguem sobreviver o mês todo com os valores recebidos do PNAE do Instituto Federal. Chego a me emocionar, porque assim... são famílias que não têm outra renda, sobrevivem da roça, mas que precisam do dinheiro do Programa para comprar roupa, sapato, remédio, e conseguem isso com o recurso do PNAE do IF Baiano, além da melhoria da alimentação para os alunos. Já fiz visitas em casas onde os pais relataram que a alimentação diária dos filhos era a comida ofertada pelo Instituto Federal de Senhor do Bonfim. (Entrevistada BA_I(af)(ex-aluna)(ex-terc)).

As revelações de BA_B(r) e BA_I(af)(ex-aluna)(ex-terc) sobre as necessidades dos alunos em relação à refeição que é servida no campus vão ao encontro do alerta feito por Rocha (1995) de que, no Nordeste, os níveis de pobrezas são alarmantes. A pobreza relaciona-se à escassez de renda, uma vez que esta representa um recurso necessário para adquirir alimentos, bens e serviços.

\title{
4.3 Análise da rede social de implementação do PNAE
}

Neste estudo, a análise de redes sociais traz uma metodologia que apreende quantitativamente as conexões entre os atores, resultando em uma fotografia da estrutura de relações em determinado momento. Para além disso, nesta pesquisa faz-se uma análise que demonstra como a estrutura desse momento se formou, reiterando a proposta aqui de retratar a estrutura como produto da história e da trajetória dos atores e da instituição.

Constatou-se que o campus conta com 15 atores atuando na operacionalização do PNAE e que cinco cursos da instituição servem de ancoragem para as ações do Programa, uma vez que eles periodicamente oferecem cursos e capacitações voltadas para o desenvolvimento rural, conforme exposto no Quadro 1.

Dos 15 atores identificados, 4 são do sexo feminino, e 11, do sexo masculino. Desse total, 7 ocupam o cargo de gestão, 5 são técnicos administrativos e 3 são fornecedores do Programa, 
sendo uma ex-aluna e ex-terceirizada da instituição. A rede recebe uma ancoragem de cinco cursos da instituição, que possuem frequentemente ações voltadas para o rural.

Na Figura 2, observa-se o número de laços que retratam a dimensão da rede, que, neste caso, é de 94 vértices/laços/ligações. Também, tem-se um exemplo dessa apresentação visual, por meio da rede distribuída, ilustrando a troca de informações entre os atores envolvidos na implementação do PNAE no IF Baiano, campus Senhor do Bonfim.

Há um total de 20 nós, portanto cada ator poderia estabelecer 19 relações. A densidade geral ${ }^{6}$ é 0,247 , o que indica uma estrutura com conexões medianas e densidade relativamente baixa. Em outras palavras, de 380 relações (links) que poderiam ser potencialmente ativadas, apenas $24,7 \%$ dos vínculos foram efetivados dentro da estrutura de relações considerada, com reciprocidade ${ }^{7}$ de $44,62 \%$. Esse valor é influenciado pela presença de alguns atores sociais que pouco interagem com os demais da estrutura, por atuarem diretamente na Reitoria, como no caso dos nós BA_C(r) e BA_D(r), mais os servidores de outros campi do IF Baiano, como $B A \_L(o c), B A \_M(o c), B A \_N(d)$, que, embora seja docente do campus, encontra-se atualmente ocupando o cargo de gestão na Reitoria, e BA_O(t), que é técnico administrativo e atualmente se encontra cedido pelo IF Baiano/SB ao IFBA de Jacobina.

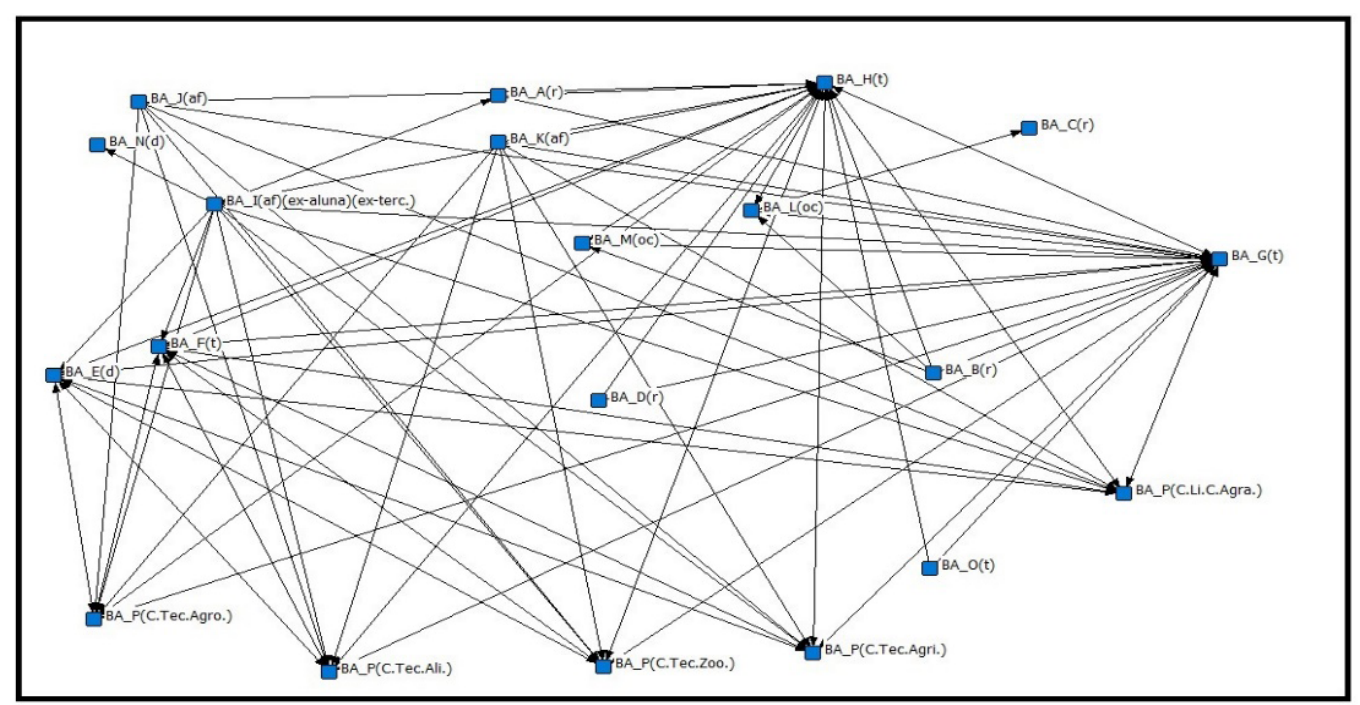

Figura 2. Rede de implementadores do PNAE do IF Baiano/SB ${ }^{8}$. Nota: o ordenamento das figuras e a distância entre os nós não determinam a força e/ou a proximidade dos atores. Fonte: elaborada pelos autores a partir dos dados da pesquisa de campo e com a utilização do software Ucinet 6 (2019).

Esse caso evidencia uma estrutura dentro da qual coexistem várias fases do processo de agregação, surgindo uma nuvem central que consiste particularmente em grupos ativos que possuem relações recíprocas e em uma periferia nas quais as relações são mais esparsas. Quanto menor a densidade, maiores as chances de as informações e os conhecimentos não circularem na rede e, com isso, causarem impactos negativos na operacionalização do Programa.

A densidade descreve o nível geral de ligação entre os atores em uma rede (Scott, 1991), uma vez que, quanto mais pontos estiverem conectados entre si, mais densa será a rede. Então, a rede mais densa é aquela em que todos os atores estão conectados entre si. A densidade

${ }^{6}$ Os resultados foram encontrados no Ucinet, por meio da rotina operacional: Network/ Cohesion/Density/Density Overall.

7 Os resultados foram encontrados no Ucinet, por meio da rotina operacional: Network/ Cohesion/reciprocity.

${ }^{8}$ Os resultados foram encontrados no Ucinet, NetDraw, por meio da rotina operacional: Open Ucinet network dataset. 
é simplesmente uma medida de até que ponto todos os atores da rede estão vinculados um ao outro e reflete ainda a coesão da rede. Em se tratando de rede total, pode-se afirmar que o indicativo de coesão é moderado, uma vez que a coesão varia de acordo com a densidade. Pode-se observar também, por meio da análise morfológica da Figura 2, a existência de fluxos relacionais bidirecionais e unidirecionais.

A densidade e a coesão são essenciais para uma rede de implementadores do PNAE, pois contribui para que a interação entre atores seja eficiente e eficaz em prol dos resultados da política pública. O nó BA_I(af)(ex-aluna)(ex-terc) é um ator externo ao IF Baiano/SB, importante para a mobilização inicial do Programa na instituição, e atualmente é um dos seus fornecedores. A história vivida por ela e os vínculos que ela criou ajudam a ampliar a compreensão do porquê de ela ter assumido a posição em que se encontra hoje. Como argumentou Steiner (2006), evidenciar os processos sócio-históricos que marcam os mercados e os atores que o integram é uma estratégia analítica para relativizar qualquer determinismo estrutural das redes e compreender seu dinamismo.

No entanto, deve-se ressaltar que BA_I(af)(ex-aluna)(ex-terc) é citada por BA_A(r) como sendo um ator importante no início da efetivação do PNAE no campus por causa de fatores como: vínculo com o rural, ex-aluna, ex-terceirizada da instituição, procurada por agricultores familiares do município para orientações e, hoje, representante de uma das cooperativas que fornecem alimentos para o campus por meio desse Programa.

Na Tabela 1, estão os números de relações outdegree (emitidas) e indegree (recebidas) que auxiliam na análise sobre a posição dos atores na rede, a centralidade e a marginalidade nessa configuração relacional associada à implementação do PNAE.

Tabela 1. Centralização dos nós (outdegree-indegree).

\begin{tabular}{|c|c|c|c|c|}
\hline Atores & $\begin{array}{c}\text { Grau de saída } \\
\text { (Outdegree) }\end{array}$ & $\begin{array}{c}\text { Grau de entrada } \\
\text { (Indegree) }\end{array}$ & $\begin{array}{l}\text { Grau de saída } \\
\text { (nOutdegree) }\end{array}$ & $\begin{array}{c}\text { Grau de entrada } \\
\text { (n/ndegree) }\end{array}$ \\
\hline BA_A(r) & 3,000 & 1,000 & 0,158 & 0,053 \\
\hline BA_B(r) & 4,000 & 0,000 & 0,211 & 0,000 \\
\hline BA_C(r) & 1,000 & 1,000 & 1,000 & 0,053 \\
\hline$B A_{-}^{-} D(r)$ & 2,000 & 0,000 & 0,105 & 0,000 \\
\hline$B A \_E(d)$ & 7,000 & 8,000 & 0,368 & 0,421 \\
\hline $\mathrm{BA} F(\mathrm{t})$ & 7,000 & 8,000 & 0,368 & 0,421 \\
\hline $\mathrm{BA}-\mathrm{G}(\mathrm{t})$ & 10,000 & 16,000 & 0,526 & 0,842 \\
\hline $\mathrm{BA} \_\mathrm{H}(\mathrm{t})$ & 10,000 & 16,000 & 0,526 & 0,842 \\
\hline $\begin{array}{l}\text { BA_I(af)(ex-aluna) } \\
\text { (ex-terc) }\end{array}$ & 11,000 & 1,000 & 0,579 & 0,053 \\
\hline$B A 」(a f)$ & 7,000 & 0,000 & 0,368 & 0,000 \\
\hline BA_K(af) & 7,000 & 0,000 & 0,368 & 0,000 \\
\hline BA_L(OC) & 1,000 & 4,000 & 0,053 & 0,211 \\
\hline BA_M(OC) & 2,000 & 3,000 & 0,105 & 0,158 \\
\hline BA_N(d) & 0,000 & 1,000 & 0,000 & 0,053 \\
\hline BA_O $(\mathrm{t})$ & 2,000 & 0,000 & 0,105 & 0,000 \\
\hline curso técnico em & 4,000 & 7,000 & 0,211 & 0,368 \\
\hline Agropecuária & & & & \\
\hline $\begin{array}{l}\text { curso técnico em } \\
\text { Zootecnia }\end{array}$ & 4,000 & 7,000 & 0,211 & 0,368 \\
\hline $\begin{array}{l}\text { curso técnico em } \\
\text { Alimentos }\end{array}$ & 4,000 & 7,000 & 0,211 & 0,368 \\
\hline $\begin{array}{l}\text { curso técnico em } \\
\text { Agrimensura }\end{array}$ & 4,000 & 7,000 & 0,211 & 0,368 \\
\hline $\begin{array}{l}\text { licenciatura em } \\
\text { Ciência Agrárias }\end{array}$ & 4,000 & 7,000 & 0,211 & 0,368 \\
\hline
\end{tabular}

Fonte: elaborada pelos autores a partir do Ucinet 6 (2020).

${ }^{9}$ Os resultados foram encontrados no Ucinet, por meio da rotina operacional Network/Centrality/Degree. 
Os atores centrais nessa rede são os técnicos administrativos, sendo a ocupação de ambos relacionada ao cargo interno de gestão, como diretor administrativo e patrimonial, e as redes desses nós podem ser visualizadas na Figura 3. Em termos de execução do PNAE no IF Baiano/ SB, quanto mais citado é um ator, mais ele aparece e é essencial na operacionalização do Programa, e quanto mais ele é lembrado pelos demais atores, mais ele é considerado um partícipe ativo. Assim, uma igualdade entre indegree e outdegree, apresentada por BA_E(d) e $B A \_F(t)$, revela que esses atores são dinâmicos na operacionalização.

Já um indegree maior do que um outdegree, como é o caso dos atores BA_G(t) e BA_H(t), demonstra que eles são essenciais para a efetivação do Programa. Esses atores foram os mais lembrados pelos respondentes durante a pesquisa, pois desempenham papéis essenciais para a rede de execução do Programa no IF Baiano/SB. Esse fato também pode ser comprovado pelo relato do entrevistado BA_A (r):

O campus conseguiu fazer a primeira chamada pública PNAE em 2012 e continuou nos anos seguintes. No entanto, as ações do Programa ficam mais eficientes quando BA_G(t) e BA_H(t) assumem a operacionalização do Programa no campus desde 2015 e fazem isso com excelência. (Entrevistado BA_A (r)).

De forma antagônica, um outdegreevisivelmente maior do que um indegree, como é o caso de BA_I(af)(ex-aluna)(ex-terc), indica que o ator coopera, mas, por atualmente ser apenas mais uma fornecedora do mercado institucional do IF Baiano/SB, ela não foi citada pelos demais. Hoje, o processo flui normalmente no campus sem o auxílio desse nó, uma vez que a relação com os agricultores familiares e/ou com suas organizações coletivas já foi consolidada.

Isso posto, o nó BA_I(af)(ex-aluna)(ex-terc) compartilha informações com o maior número de atores (outdegree $=11$ ), pois, sendo uma fornecedora, ela necessita, assim como os demais fornecedores do mercado institucional, manter contato com os atores que operacionalizam o PNAE na instituição. O resultado indica que os nós BA_G(t) e BA_H(t) possuem maior capacidade de articulação na rede, uma vez que têm o maior somatório outdegree e indegree (= 36). A informação identifica que esses nós exercem o papel de intermediários na rede.

Complementando os achados de outdegree e indegree da rede analisada, para verificar os indicadores de influência de um ator sobre os outros, novamente os atores com destaque são $B A \_G(t)$ e BA_H(t), com valor elevado de poder em relação aos demais, o que demonstra a facilidade de intermediação e de comunicação desse nó em relação aos outros. E ainda, os nós BA_G(t) e BA_H(t) apresentam o maior grau de proximidade, o que evidencia a alta capacidade desse nó de se ligar a todos os atores da rede.

No entanto, o nó BA_F(t) apresentou o menor índice. Com relação a esse baixo índice, durante a pesquisa de campo BA_F(t) argumenta que:

A operacionalização do PNAE no campusfoi delegada ao BA_G(t) e BA_H(t), por sua função e por sua aproximação com a agricultura familiar, mas que ambos, BA_G(t) e BA_H(t), trabalham em sintonia, e a comunicação entre os setores de nutrição e compras/licitação, isso faz toda a diferença. (BA_F(t)).

Outra métrica utilizada para analisar a influência que um nó exerce sobre o fluxo de informações na rede de executores do PNAE no IF Baiano/SB foi a Betweenness Centrality. Observa-se que os nós BA_G(t), BA_H(t) e BA_I(af)(ex-aluna)(ex-terc) servem como pontes de uma parte do gráfico para outra, configurando-se em conexões principais na rede (Figura 3). 


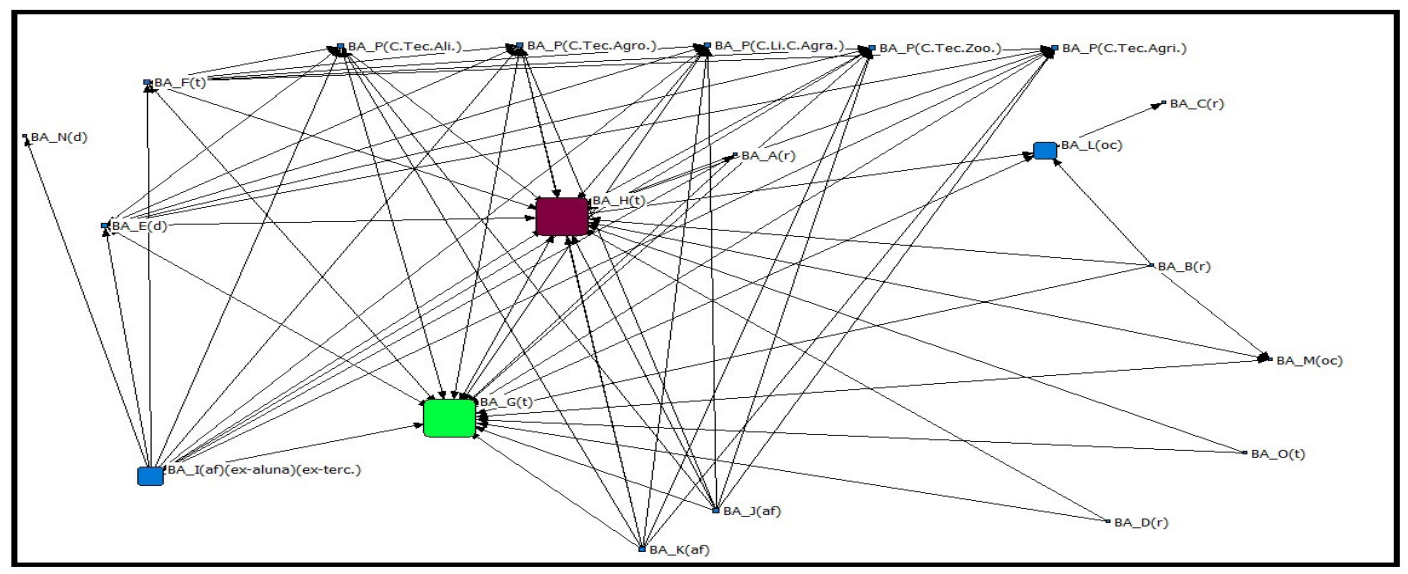

Figura 3. Centralidade de intermediação (Betweenness Centrality) ${ }^{10}$. Fonte: elaborada pelos autores a partir do Ucinet 6 (2020).

Se os nós BA_G(t) e BA_H(t) e/ou BA_I(af)(ex-aluna)(ex-terc) forem removidos, as conexões no gráfico ficam desestruturadas, o que torna esses atores extremamente importantes para a configuração atual, com o papel de assegurar que os demais atores não sejam isolados. Sendo esses atores elementos-chave para que a conexão interna da rede ocorra, a atuação desses implementadores enriquece a conexão com os outros atores da rede e oportuniza novos conhecimentos referentes aos processos de operacionalização do PNAE. Além disso, esses implementadores exercem o papel de pontes, ao intermediarem (Betweenness) a comunicação entre pares de nós centrais e periféricos na rede. Assim, a posição dos atores-chave é um subsídio que intervém em suas conjunturas, principalmente porque define suas capacidades de acesso e controle dentro da rede.

Destaca-se ainda que, à medida que essa rede se ampliar ou se, porventura, ocorrer uma diversificação dos atores envolvidos, a natureza das relações pode se alterar e automaticamente mudar a morfologia da rede de implementação. Isso destaca, novamente, o caráter dinâmico das redes sociais, como apontou Steiner (2006), e ressalta também a demanda por pesquisas que assumam a dimensão histórica impressa na estrutura das redes. Além disso, essa percepção relativiza o estruturalismo determinista que muitas análises de redes sociais têm assumido, dando relevo à capacidade de agência dos atores na construção dos mercados e na implementação das políticas públicas.

Deve ser ressaltado que os nós BA_G(t) e BA_H(t) possuem vínculos familiares no município de Senhor do Bonfim. Além disso, eles estão na gestão do campus e possuem vários recursos disponíveis, como contatos, aproximação com os técnicos administrativos, informações e status, ou seja, atributos relevantes para constituírem conexões sociais e assumirem centralidade na rede. Assim, a compreensão de que as relações sociais assumem papéis centrais em um contexto de implementação endossa os pressupostos de embeddedness evidenciados por Granovetter (1985).

Como citado, o nó BA_I(af)(ex-aluna)(ex-terc) estudou e trabalhou como terceirizada na instituição, é natural do município de Senhor do Bonfim, possui vínculo com o meio rural e hoje está como representante de uma cooperativa de agricultores familiares. Essas particularidades da vida e trajetória dos nós BA_G(t), BA_H(t) e BA_I(af)(ex-aluna)(ex-terc) propiciaram que esses atores, ao longo dos anos no serviço público, criassem laços tanto com a instituição e

${ }^{10}$ Os resultados foram encontrados no Ucinet, NetDraw, por meio da rotina operacional: Analysis/Centrality Measures/ Betweenness. 
os servidores quanto com os habitantes locais e regionais. Isso é de grande relevância para o estudo, pois, como enfatiza Granovetter (1985), o comportamento e as escolhas dos atores sociais consistem em um sistema de interação, e esta, por sua vez, rompe com a concepção atomizada de ação econômica e apresenta a questão da imersão da atividade econômica no tecido social.

Foi possível perceber a complementaridade que as análises do mapeamento da rede de implementação e a análise de suas configurações proporcionaram aos dados qualitativos. A rede analisada retrata os níveis relacionais e institucionais como poucos atores envolvidos na efetivação do Programa no campus Senhor do Bonfim. Esse fato ocorre pelo comprometimento da instituição com a extensão, o que com faz que as capacitações oferecidas aos agricultores familiares no decorrer do ano estimulem e dinamizem o acesso dessa categoria de trabalhadores ao mercado institucional de alimentos. Além disso, essa aproximação histórica da instituição com os agricultores familiares possibilita que o IF Baiano/SB identifique as necessidades e os desafios desse grupo e crie cursos práticos que solucionem os problemas encontrados. Conclui-se que não são necessários vários atores para operacionalizar o PNAE, uma vez que a instituição faz isso coletivamente no decorrer de sua trajetória.

\section{CONSIDERAÇÕES FINAIS}

Este trabalho se dedicou a elucidar as reflexões sobre a implementação de políticas públicas, mais especificamente a implementação do PNAE no IF Baiano/SB, construindo uma abordagem relacional e desvelando aspectos sócio-históricos que influenciaram a operacionalização e os resultados do Programa. Nessa empreitada, especial atenção foi dada aos atores implementadores, aos vínculos estabelecidos entre eles durante o processo de implementação, às suas percepções sobre o PNAE, aos acordos estabelecidos e às suas práticas localmente contextualizadas. Ajustar o recorte analítico da pesquisa sob o ângulo relacional possibilitou dar proeminência à agência dos atores e compreender sua relação recíproca com a estrutura da rede e os dispositivos institucionais que condicionam o Programa.

O reconhecimento de elementos condicionantes do envolvimento dos atores na rede de implementadores contribuiu para a operacionalização empírica da noção de social embeddedness. Pode-se inferir, assim, que é central para análise de políticas públicas evidenciar os processos políticos (politics) subjacentes à instrumentalização burocrática e à implementação do Programa, dotando os atores de agência. Espera-se que este trabalho contribua para que novos empreendimentos teóricos possam se edificar sobre uma abordagem relacional, centrada nos atores, superando a ênfase normativa da policy, apropriando-se do Estado como um dos atores, e não centralizando excessivamente a implementação pública à ação governamental.

Percebe-se que os atores e suas interações, definindo diferentes configurações relacionais ao longo do tempo, particularizam os resultados das políticas públicas e moldam a sua trajetória. No campo aqui em tela, isso foi destacado, mostrando como o histórico do IF Baiano, de aproximações sucessivas com os agricultores familiares, por meio da extensão, e as características de alguns atores como pontes entre diferentes redes dinamizaram o acesso da agricultura familiar ao PNAE. A pesquisa revelou também que as relações sociais, estruturadas em rede, não ocorrem em um vácuo institucional, mas encorajadas ou desestimuladas por diferentes dispositivos institucionais, alguns formais, associados à burocracia pública, outros informais, acordados entre os próprios atores no âmbito de suas interações.

Constatou-se que a dinâmica de implementação do Programa no IF Baiano/SB não foi determinada pela configuração institucional da política pública, mas sim pela gênese da 
instituição, por suas redes de relações, pelo modo como os atores implementadores interagem entre si e pelas regras construídas. Nessa linha de argumentação, a característica morfológica da rede social de implementação do PNAE no IF Baiano, com atores centrais assumindo a conexão entre diferentes redes (compradores e fornecedores) e construindo maior coesão, tem contribuído para ampliar a efetividade do Programa e oportunizar o acesso da agricultura familiar a esse mercado institucional. Contudo, conclui-se também que a natureza das relações estabelecidas é fundamental para compreender a dinâmica das redes. O vínculo de proximidade e confiança entre os atores centrais que conectam o IF Baiano à agricultura familiar no caso aqui analisado, cujo lastro histórico e a relação de trabalho e amizade antecedem o PNAE, foi a base para operar a compra institucional e viabilizar acordos que facilitam a participação dos agricultores familiares. Reside aí os esclarecimentos sobre por que encontramos diferentes compassos e trajetórias das políticas públicas em contextos locais.

Logo, este resultado requer ampliação dos estudos para outras instituições, não só da rede federal de ensino, mas também das redes municipal e estadual, para se ter um panorama da operacionalização do PNAE nas escolas públicas brasileiras. Cabe aqui salientar que a experiência do IF Baiano na implementação do PNAE pode servir de exemplo e orientação para outras escolas públicas, percebendo seus limites e suas oportunidades para delinear processos de implementação que garantam maior densidade às redes sociais e criem mecanismos efetivos para regulação das ações dos atores e normatização da compra institucional de alimentos, como também pode instigar novos estudos sobre implementação de políticas públicas, fazendo emergir elementos encobertos na estrutura normativa com foco nos atores que operacionalizam as políticas públicas e suas relações.

\section{REFERÊNCIAS}

Allaire, G. A. (2013). Contribuição da sociologia econômica para compreender o significado da qualidade nos mercados alimentares. In P. A. Niederle (Ed.), Indicações geográficas: qualidade e origem nos mercados alimentares (pp. 55-80). Porto Alegre: UFRGS.

Autry, C. W., \& Griffis, S. E. (2008). Supply chain capital: the impact of structural and relational linkages on firm execution and innovation. Journal of Business Logistics, 29(1), 157-173.

Bardin, L. (2011). Análise de conteúdo. Lisboa: Edições Setenta.

Borgatti, S. P., \& Li, X. (2009). On social network analysis in a supply chain context. The Journal of Supply Chain Management, 45(2), 5-22.

Borgatti, S. P., Everett, M. G., \& Freeman, L. C. (2002). Ucinet for Windows: software for social network analysis. Harvard: Analytic Technologies.

Duarte, D. N., \& Dias, M. M. (2012). Rede de comercialização, políticas públicas e mudanças na ação extensionista: o caso de Iconha-ES. Extensão Rural, 19, 105-136.

Freitas, A. F. (2015). Dinâmicas sociais e desenvolvimento territorial no território Serra do Brigadeiro: atores, redes e instituições (Tese de doutorado). Centro de Pós-graduação e Pesquisas em Administração, Universidade Federal de Minas Gerais, Belo Horizonte.

Freitas, A. F. D. (2017). Dinâmicas locais de implementação do Programa Nacional de Alimentação Escolar: uma abordagem relacional(Tese de doutorado). Departamento de Economia Rural, Universidade Federal de Viçosa, Viçosa.

Friedland, R., \& Alford, R. R. (1991). Bringing society back: symbols, practices and institutional contradictions. In W. W. Powell \& P.J. Dimaggio (Eds.), The new institutionalism in organizational analysis (Cap. 10, pp. 232-263). Chicago: University of Chicago Press. 
Gil, A. C. (2017). Como elaborar projetos de pesquisa (6. ed.). São Paulo: Atlas.

Granovetter, M. (1973). The strength of weak ties. American Journal of Sociology, 78(6), 1930-1938.

Granovetter, M. (1985). Getting a job: a study of contacts and careers (2nd ed.). Chicago, University of Chicago Press.

Hall, P. A., \& Taylor, R. C. R. (2003). As três versões do neo-institucionalismo. Lua Nova, (58), 193-223.

Instituto Federal de Educação, Ciência e Tecnologia Baiano. (2019). Resolução n.22 de 18 de março de 2019, que dispõe da Regulamentação das Atividades Docentes (RAD). Instituto Federal de Educação, Ciência e Tecnologia Baiano, Salvador. Recuperado em 17 de dezembro de 2020, de https://ifbaiano.edu.br/portal/wp-content/uploads/2019/04/ Resolu\%C3\%A7\%C3\%A3o-22-2019.pdf

Lipsky, M. (1976).Toward a theory of street-level bureaucracy. In W. Hawley \& M. Lipsky (Eds.), Theoretical perspectives on urban politics. Eaglewood Cliffs: Prantice Hall

Lotta, G. S. (2010). Implementação de políticas públicas: o impacto dos fatores relacionais e organizacionais sobre a atuação dos burocratas de nível de rua no Programa Saúde da Família (Tese de doutorado). Departamento de Ciência Política, Universidade de São Paulo, São Paulo.

Pena, R. F. A. (2020). Josué de Castro. Brasil Escola. Recuperado em 18 de fevereiro de 2020, de https://brasilescola.uol.com.br/geografia/josue-castro.htm

Pereira, A. S., Shitsuka, D. M., Parreira, F. P., \& Shitsuk, R. (2018) Metodologia da pesquisa cientifica (1. ed.). Santa Maria: UAB/NTE/UFSM.

Plataforma Nilo Peçanha - PNP. (2020). Recuperado em 18 de fevereiro de 2020, de https:// www.plataformanilopecanha.org

Polanyi, K. (1980). A grande transformação: as origens de nossa época. Rio de Janeiro: Campus.

Rocha, S. (1995). Governabilidade e pobreza: o desafio dos números (Texto para Discussão, No. 368). Brasília: IPEA.

Scott, W. R. (1991). Unpacking institutional arguments. In W. W. Powell \& P. J. DiMaggio (Eds.), The new institutionalism in organizational analysis (pp. 164-182). Chicago: The University of Chicago Press.

Serva, M., \& Andion, C. (2006). Teoria das organizações e a nova sociologia econômica: um diálogo interdisciplinar. Revista de Administração de Empresas, 46(2), 10-21.

Silva, M. G., Dias, M. M., \& Silva, S. P. (2014). Relações e estratégias de (des)envolvimento rural: políticas públicas, agricultura familiar e dinâmicas locais no município de Espera Feliz (MG). Revista de Economia e Sociologia Rural, 52(2), 229-248.

Steiner, P. (2006). A sociologia econômica. São Paulo: Atlas.

Swedberg, R. (2004). Sociologia econômica. Tempo Social, (2), 7-34.

Troian, A., Troian, A., Oliveira, S. V., \& Pereira, J. C. (2020). Desempenho dos municípios do Rio Grande do Sul na execução dos recursos do PNAE com a agricultura familiar. Revista de Economia e Sociologia Rural, 58(3), e204558.

Vilela, K. F., Braga, G. B., Barbosa, R. A., Silva, V. X., Campo, P. M., Almeida, M. T., Chaves, J. V., \& Cruz, M. M. R. N. (2020). Public purchases execution in the technological, science and educational institutes: an analysis of the national school feeding program from 2013 to 2018. Revista de Extensão e Estudos Rurais, 9(1), 101-122. 
Vilela, K. F., Freitas, A. F., Barbosa, R. A., \& Salgado, R. J. S. F. (2019). Implementation of the national school nourishment program in the Brazilian Federal institution of education of Bahia State. Ciência Rural, 49(9), e20190105.

Wasserman, S., \& Faust, K. (1994). Análise de redes sociais: métodos e aplicações. Cambridge: Universidade de Cambridge.

Wilkinson, J. (2002). Sociologia econômica, a teoria das convenções e o fortalecimento dos mercados. Ensaios FEE, 23(2).

Yin, R. K. (2015). O Estudo de caso. Porto Alegre: Bookman. 